\title{
Role of Infrared Spectroscopy in Coal Analysis-An Investigation
}

\author{
Manoj Balachandran \\ Department of Physics, Christ University, Bangalore, India \\ Email: manoj.b@christuniversity.in
}

Received 25 February 2014; revised 27 March 2014; accepted 4 April 2014

Copyright (C) 2014 by author and Scientific Research Publishing Inc.

This work is licensed under the Creative Commons Attribution International License (CC BY). http://creativecommons.org/licenses/by/4.0/

(c) (i) Open Access

\section{Abstract}

Fourier transform infrared (FT-IR) spectroscopy is a widely used analytical technique for determining the different functional groups of a coal structure. This method, being able to reveal carbohydrogenated structures (aromatic and aliphatic) and heteroatomic functions (mainly oxygenated), as well as to detect the presence of minerals, is currently one of the most powerful techniques for coal characterization and thus is of paramount importance in the various utilization procedures of coal (industrial combustion, coke production processes, etc.). FT-IR study shows the presence of aliphatic $-\mathrm{CH},-\mathrm{CH}_{2}$ and $-\mathrm{CH}_{3}$ groups, aliphatic $\mathrm{C}-\mathrm{O}-\mathrm{C}$ stretching associated with $-\mathrm{OH}$ and -NH stretching vibrations and HCC rocking. It is conjectured that, the two-stage leaching using $\mathrm{HNO}_{3}$ followed by $\mathrm{HF}$ remarkably reduced the ash content as well as the minerals including $\mathrm{Al}, \mathrm{Si}$ and $\mathrm{Ca}$. The solubilization of samples with buffered EDTA could not eliminate the minerals in coal. The silicate and kaolinite bands showed a systematic lowering on EDTA and carboxylic acid treatment. The fungal leaching was most beneficial for aromatic molecules with different degrees of substitution. The intensity of bands due to carbonyl groups was increased, when treated with fungi, whereas that due to oxygen functional groups showed a reverse trend. The mineral bands due to silicates also decreased in intensity, on post treatment with fungal culture.

\section{Keywords}

Coal, Leaching, FT-IR, Bioleaching, Organic Acid

\section{Introduction}

By origin, coal is a heterogeneous material consisting both carbonaceous and inorganic material. The acceptance of it for a particular industry decisively depends on both of these constituents. The organic structure of coal can be regarded as consisting of heterogeneous aromatic structures, with aromaticity increasing from low to high 
rank coals. The organic part of coal also contains sulphur, oxygen, and nitrogen in functional groups. Fourier transform infrared (FT-IR) spectroscopy is a widely adapted analytical technique for determining the different functional groups in coal structure [1]-[6]. This technique, being able to reveal carbo-hydrogenated structures (aromatic and aliphatic) and heteroatomic functions (mainly oxygenated), as well as to perceive the presence of minerals, is presently one of the most powerful techniques for coal characterization and thus is of vital role in various utilization procedures of coal. The presence of mineral matter is considered as detrimental in coal utilization, preparation and transportation. Coal preparation is aimed at reducing the quantity of mineral matter and the efficient use of methods chosen depends on its concentration. They may exist as a separate entity or bonded with organic components of coal. Prior to the structural analysis, demineralization is essential, because minerals, silica in particular, would distort the functional groups which in turn affect the prominent characteristics of coals.

Though research on demineralization and characterization of coal has been reported globally, substantial research on spectroscopic characterization is still scarce. Chemical leaching of coal using acid and alkali solutions helps to reduce ash forming minerals to a large extent. These processes, either alone or followed by a physical technique, are extensively used for the production of clean coal. The general approach followed to upgrade low rank coal has involved leaching under a variety of conditions.

The approach of bioleaching with microbes in combination with dilute acids has been studied worldwide and is extremely effective when the concentration of minerals is very low. It is the extraction of metals from their ores through the use of living microorganisms, where several species of fungi are used. But the processes have not reached widespread commercialization largely due to two reasons. In this scenario, a combined leaching procedure using strong mineral acids, mild organic acids and microbial treatment was developed for demineralization of low rank sub-bituminous coal and the results are summarized.

\section{Materials and Methods}

Demineralization of coal prior to FT-IR characterization is carried out on well powdered sample. Successive leaching with mineral acid, organic acid, treatment with carboxylic acid and various filamentous fungi are also carried out. The scheme of leaching (Figure 1) is depicted below [6]-[13].

Demineralization was carried out using hydrofluoric acid. It was modified to include dil. $\mathrm{HNO}_{3}$ as the first reagent followed by HF in different concentrations. In the initial stage, $50 \mathrm{~g}$ of coal sample was mixed with 100 $\mathrm{ml}$ dil. $\mathrm{HNO}_{3}(5 \%)$ solution in a $500 \mathrm{ml}$ teflon beaker and stirred for an hour at $30^{\circ} \mathrm{C}$. In the next stage of leaching, $10 \mathrm{~g}$ of filtrate was further treated with $100 \mathrm{ml}$ concentrated HF (10\% and 40\%) for one hour. As an alternative approach, $50 \mathrm{~g}$ of sample was washed with $100 \mathrm{ml}, 0.1 \mathrm{~N}$ EDTA for $24 \mathrm{~h}$ followed by leaching in acetic acid column $(2 \mathrm{~N})$ over a period of $1 \mathrm{~h}$ and $2 \mathrm{~h}$ respectively. The resulting samples were recovered by filtration and cleaned repeatedly using de-ionized water. The dried samples were tested for ultimate analysis and subjected to spectroscopic characterizations.
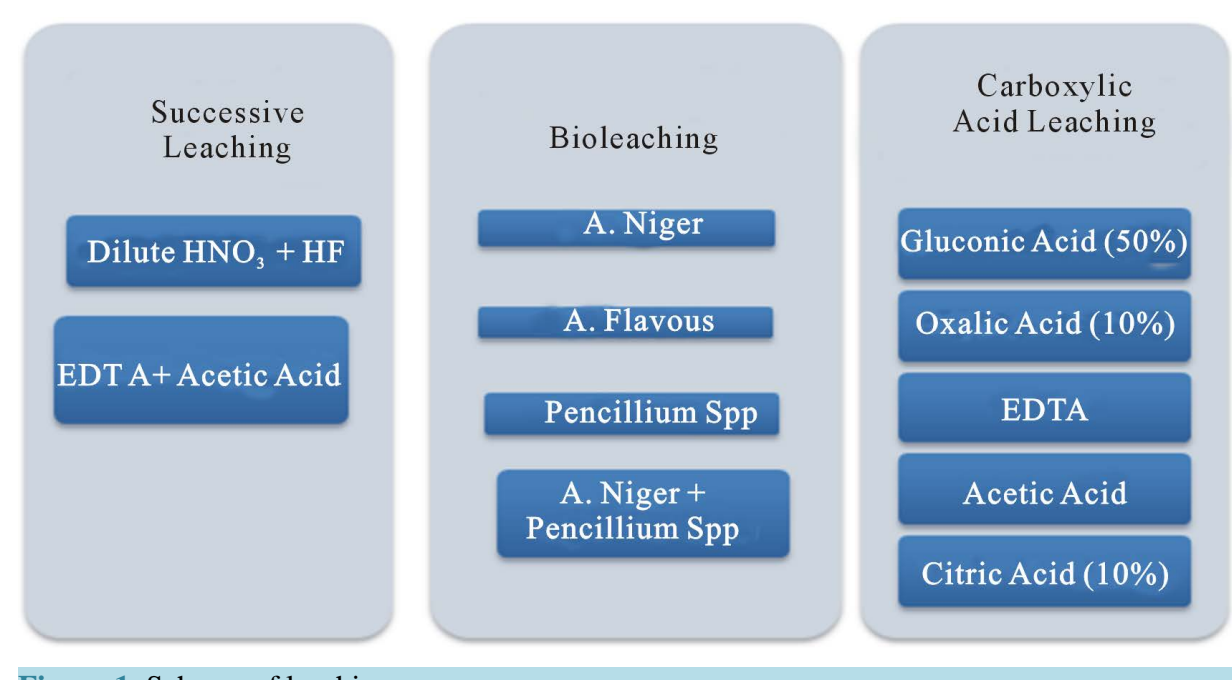

Figure 1. Scheme of leaching. 
Bituminous coal was air-dried and ground to the particle size $<75 \mu \mathrm{m}$, of which $50 \mathrm{~g}$ was treated, employing carboxylic acids like gluconic acid (50\%), oxalic acid (10\%), EDTA, acetic acid and citric acid (10\%) separately in a $500 \mathrm{ml}$ teflon beaker for $24 \mathrm{~h}$ at room temperature $\left(27^{\circ} \mathrm{C}\right)$. The sample was recovered from the respective organic acid solution by filtration using a poly-propylene funnel.

About 10 g selected coal samples were dried, ground to a particular size and inoculated into $200 \mathrm{ml}$ modified Czepek Dox medium with low sucrose. Cultures of A. niger, A. flavus and Penicillium spp were grown on potato dextrose agar medium till sporulation. The spores were inoculated in modified Czepek Dox medium containing coal sample as four different sets A. niger (AS), A. flavus (FL), Penicillium spp (PE) and mixed culture of A. niger and Penicillium spp (APE). The FT-IR spectra of samples were recorded over the range, $4000-500 \mathrm{~cm}^{-1}$ on a Shimadzu FT-IR spectrometer using KBr pellet technique.

\section{Results and Discussion}

\subsection{Vibrational Spectroscopic Analysis of Successively Leached Coal}

The FT-IR spectra of coal solubilized with different reagents are recorded in Figure 2. Samples leached with acetic acid and EDTA (GEA1-GEA3-1 hr to $3 \mathrm{hrs}$ ) showed sharp bands at 540 and $1030 \mathrm{~cm}^{-1}$, which are assigned to the vibration of Si-O-Si in quartz and kaolinite [1]-[4]. The peaks at 2920 and $2850 \mathrm{~cm}^{-1}$ are due to the existence of aliphatic groups in coal samples and that at $1600 \mathrm{~cm}^{-1}$ corresponds to aromatic $\mathrm{C}=\mathrm{C}$ structure. The symmetric deformation associated with $-\mathrm{CH}_{3}$ group is observed at $1398 \mathrm{~cm}^{-1}$. The complex band $(900-700$ $\mathrm{cm}^{-1}$ ) indicates the aromatic structures within the coal. The spike at $670 \mathrm{~cm}^{-1}$ is ascribed to C-S band. The vibrational frequencies of oxygen in C-O-R structure spread from 1149 to $1016 \mathrm{~cm}^{-1}$. The presence of illite and kaolinite, due to poor demineralization by organic acid, is confirmed. The $1350-1000 \mathrm{~cm}^{-1}$ band is complex, because of the contribution of different functional groups and mineral matter in the acetic acid leached samples. Several functional and mineral groups are found to be absent, which reveals that, HF treatment has the potential to demineralize coal successfully [6]-[9].

It is therefore conjectured that, the two-stage leaching using $\mathrm{HNO}_{3}$ followed by $\mathrm{HF}$ remarkably reduced the ash content as well as the minerals including $\mathrm{Al}, \mathrm{Si}$ and $\mathrm{Ca}$. The results showed lack of oxidation in the organic structure of coal during the process. The solubilization of samples with buffered EDTA could not eliminate the minerals in coal.

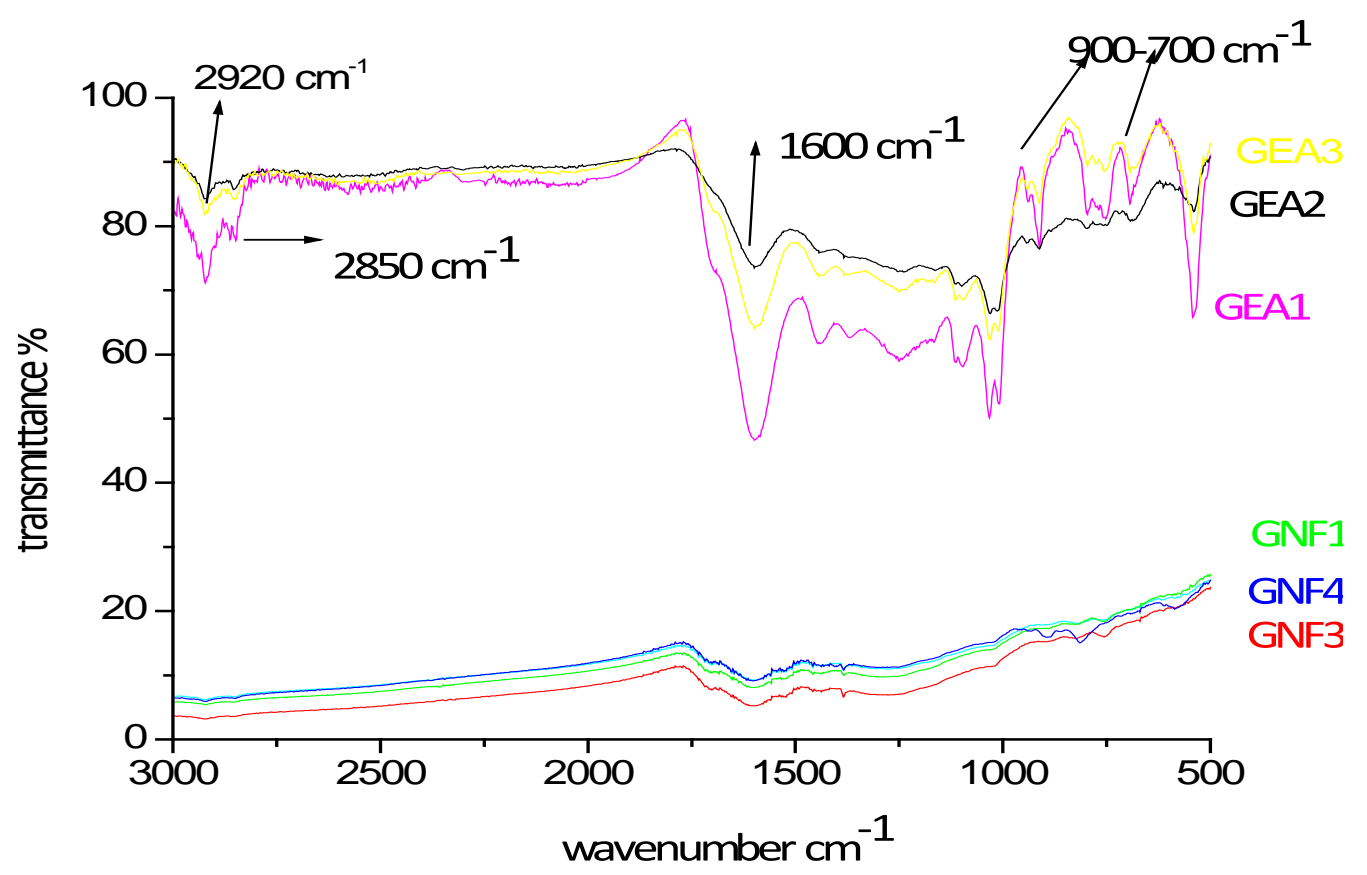

Figure 2. FT-IR spectra of demineralized coal samples (GEA1-GEA3-Acetic acid and EDTA leached samples for $1 \mathrm{hr}$ to $3 \mathrm{hr}$. GNF1-GNF3-Nitric acid and HF leached coal samples $10 \%$ to $30 \%$ ). 


\subsection{Vibrational Mode Analysis of Carboxylic Acid Leached Coal}

The vibrational spectroscopy is a pre-requisite for the analysis of functional groups in a complex material, which triggered the identification of prominent bands in virgin and leached bituminous coal (and Figure 3). Intense bands observed at $540 \mathrm{~cm}^{-1}, 3618 \mathrm{~cm}^{-1}$ and $3696 \mathrm{~cm}^{-1}$ are attributed to clay, silicate, kalonite and illite minerals [5]-[8]. The presence of a broad and strong band observed in all the samples at $3640 \mathrm{~cm}^{-1}$ could be assigned to hydroxyl stretching vibrations. The sharp intense bands $\left(2920\right.$ and $\left.2850 \mathrm{~cm}^{-1}\right)$ represent the valency oscillations of $-\mathrm{CH}_{3}$ and $-\mathrm{CH}_{2}$ aliphatic groups. In very low rank coals, the intensity of peak at $2920 \mathrm{~cm}^{-1}$ is found to be very small, because a part of the aliphatic - $\mathrm{CH}$ hydrogen is substituted by hydroxyl groups. A great abundance of $\mathrm{C}=\mathrm{O}$ and C-O-R is revealed by the presence of high intensity peaks in $1800-1000 \mathrm{~cm}^{-1}$ region [10]-[15]. A weak absorption in the spectra is noted for the samples leached with organic acids, similar to the observations of Supaluknari et al. [15] in the case of oxygen rich Australian brown coals. Manoj [5]-[10] have reported an elaborate discussion on the assignment of $1600 \mathrm{~cm}^{-1}$ band of carbons. The band associated with low rank coals and chars has been assigned to aromatic ring stretch of small, discrete entities. In the present investigation, this band became distinct with organic acid leaching, indicating an increase in carbon content. The band at $1375 \mathrm{~cm}^{-1}$ is normally present in low rank coals, whose intensity decreases in the solubilized product and is due to the stretching modes of methylene and methyl groups. The weak broad band observed at $1030 \mathrm{~cm}^{-1}$ is attributed to C-O stretching of phenolic groups and trace amount of silicate minerals associated with the samples.

The silicate and kaolinite bands showed a systematic lowering on EDTA and carboxylic acid treatment. The leaching procedure has driven a partial decrease in the intensity of mineral bands. Thus the investigations by FTIR analysis offered a crystal clear manifestation of the samples.

\subsection{Spectral Analysis Bio-Solubilized Coal}

In the present work, FT-IR spectroscopy has been used to obtain information on changes in the molecular structure of coal. The FT-IR spectra of bio-solubilized coal samples are illustrated in Figure 4. Sharp intense bands were observed at 2920 and $2850 \mathrm{~cm}^{-1}$ for all the samples, which could be due to the valency oscillations of $-\mathrm{CH}_{3}$ and $-\mathrm{CH}_{2}$ aliphatic groups. This might also arise from the stretching vibrations of -CHO group as reported by Basaran et al. [2]. Of these, the band at $2850 \mathrm{~cm}^{-1}$ was assigned to methoxy groups. The sharpness of bands in the selected samples indicated the probable age of coal belonging to tertiary formations. In very low rank coals, the intensity of $2920 \mathrm{~cm}^{-1}$ band will be very small because, the proportion of aliphatic $-\mathrm{CH}_{3}$ hydrogen is substi-

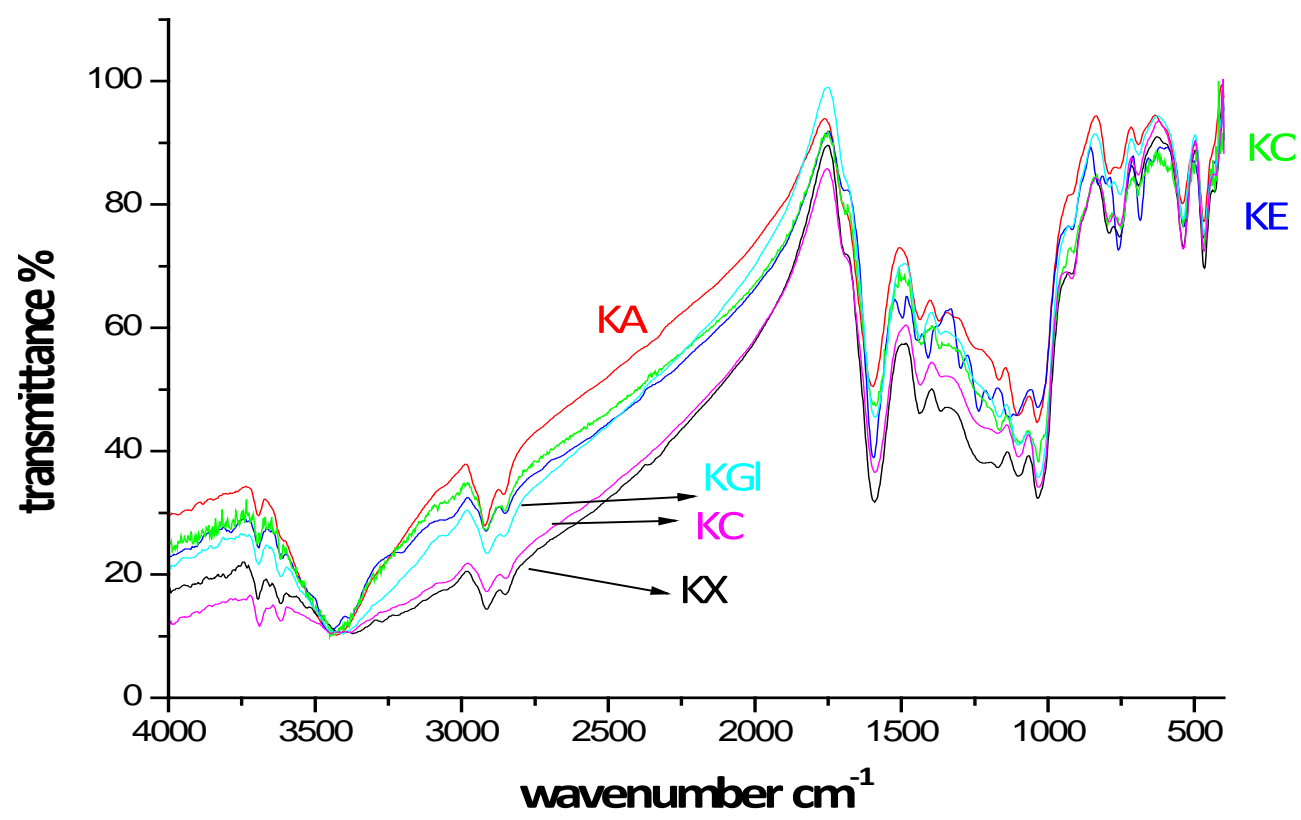

Figure 3. FT-IR spectra of chemical leached samples (KX-Virgin coal, KC-Citric acid, KGl-Gluconic acid, KA-Acetic acid, KE-EDTA, KO-Oxalic acid leached coal samples respectively). 


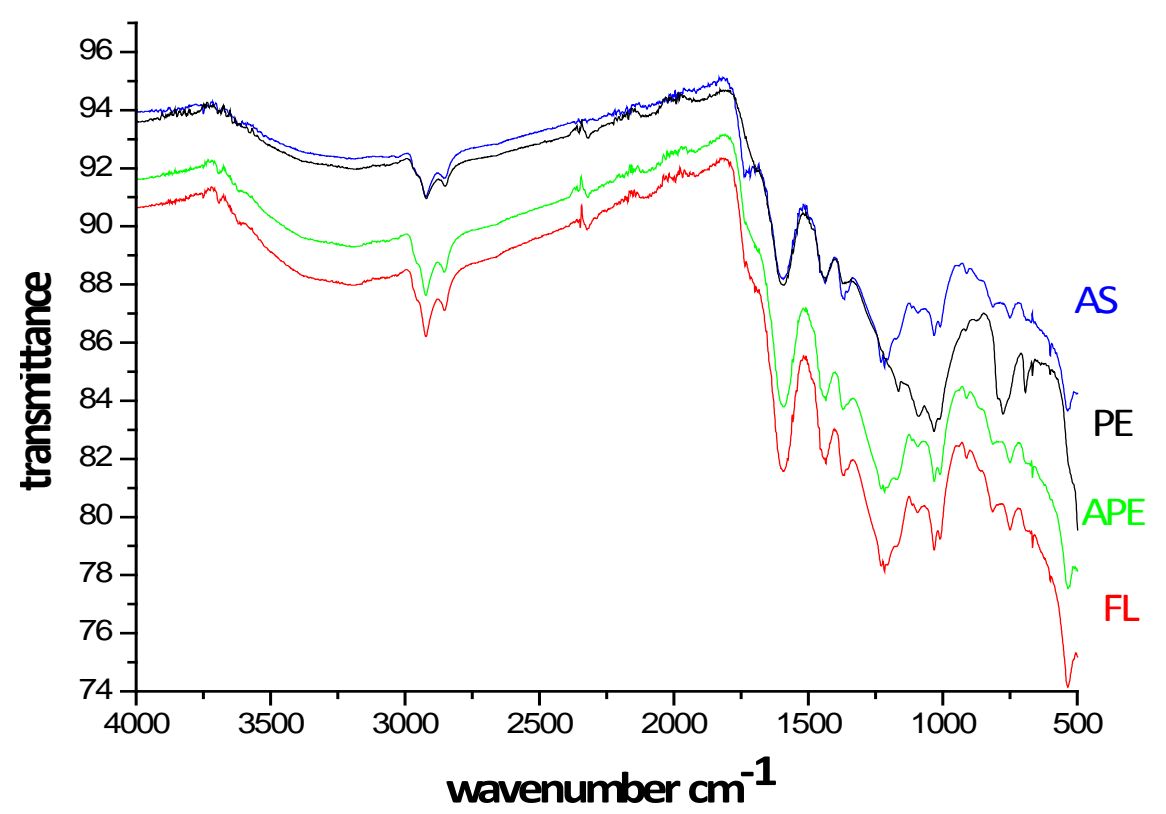

Figure 4. FT-IR spectra of bioleached samples (AS-A. niger, PE-Penicillium spp, APEMixed culture, FL-A. flavus leached coal samples).

tuted by hydroxyl groups [8] [12]-[14].

The sub-bituminous coals showed medium absorption, as they are moderately ranked. The medium intensity band at $1460 \mathrm{~cm}^{-1}$ is due to the scissoring (bending) vibration of $-\mathrm{CH}_{2}$ group next to the carbonyl group. Its first overtone coupled with the absorption due to aliphatic $-\mathrm{CH}_{3}$ vibrations appear as a strong band at $2924 \mathrm{~cm}^{-1}$. Sub-bituminous coal samples have large absorptivities for different aliphatic-CH bonds, the highest being most likely for those in long chain methylene structure [6].

The aromatic $\mathrm{C}=\mathrm{C}$ stretching vibrations $\left(1635-1600 \mathrm{~cm}^{-1}\right)$ caused strong absorption, indicating more carbon content. This is possible by the reduction of oxygen via transformation of $\mathrm{C}=\mathrm{O}$ to $\mathrm{CH}_{2}$ or due to decarboxylation of the matrix, which in turn improved the quality of carbon, hydrogen and hence the calorific value. A. flavus (FL) and mixed culture leached coal exhibited maximum intensity of absorption at $1600 \mathrm{~cm}^{-1}$, while minimum in the case of A. niger (AS) and Penicillium spp (PE). On comparing the spectrum, a remarkable absorption near $1440 \mathrm{~cm}^{-1}$ was observed for all samples, marking the presence of methyl groups. The bands at 1541 and 1442 $\mathrm{cm}^{-1}$ are normally present in immature coals with more lignin content. These bands were diminished from strong absorption to weak, in the spectra of solubilized product of AS and PE, revealing the effectiveness of Penicillium spp and A. niger insolubilizing the lignin. The band at $1375 \mathrm{~cm}^{-1}$ was ascribed to the absorption of methyl symmetric bending vibrations in tertiary butyl groups, which is normally present in low rank coals [7]-[10] [13]-[15]. The intensity of hydroxyl stretching vibrations $\left(1410-1310 \mathrm{~cm}^{-1}\right)$ was found to be decreased. The intensity of aliphatic stretching - $\mathrm{CH}$ stretching $\left(2980-2845 \mathrm{~cm}^{-1}\right)$, asymmetric $-\mathrm{CH}_{2}$ and $-\mathrm{CH}_{3}$ bending (1485 - $1400 \mathrm{~cm}^{-1}$ ) vibrations also decreased moderately, when treated with Penicillium spp (PE) and A. niger (AS). The silicate bands at 1010, 1030 and $1090 \mathrm{~cm}^{-1}$ exhibited minimum absorption after bio-leaching. The FT-IR analysis confirmed the modification of functional groups of coal on bio-solubilization. Many characteristic functional groups of low rank coals probably decreased the resistance towards the activity of microbial organisms. The fungi is proved to be effective for low rank coals, which contained phenolic, carboxylic, carbonylitic functional groups, methylene, oxygen and sulphur bridges, exchangeable cations and non-condensed aromatic rings. From the experimental trials, it was proved that, Penicillium spp and A. niger were more effective in solubilizing silicate minerals than A. flavus.

\section{Conclusion}

It is conjectured that, the two-stage leaching using $\mathrm{HNO}_{3}$ followed by HF remarkably reduced the ash content as well as the minerals including $\mathrm{Al}$, Si and $\mathrm{Ca}$. The results showed lack of oxidation in the organic structure of 
coal during the process. The solubilization of samples with buffered EDTA could not eliminate the minerals in coal. The silicate and kaolinite bands showed a systematic lowering on EDTA and carboxylic acid treatment. The leaching procedure has driven a partial decrease in the intensity of mineral bands. Thus the investigations by FT-IR analysis offered a crystal clear manifestation of the samples. The fungal leaching was most beneficial for aromatic molecules with different degrees of substitution. The intensity of bands due to carbonyl groups was increased, when treated with fungi, whereas that due to oxygen functional groups showed a reverse trend. The mineral bands due to silicates also decreased in intensity, on post treatment with fungal culture.

\section{References}

[1] Andreas, G., Andreas, I. and Victoria, K. (2003) Study of Low Rank Greek Coals Using FT-IR Spectroscopy. Energy sources, 25, 995-1005.

[2] Başaran, Y., Denizli, A., Sakintuna, B., et al. (2003) Bio-Liquefaction/Solubilization of Low-Rank Turkish Lignites. Energy Fuel, 17, 1068-1074. http://dx.doi.org/10.1021/ef020210s

[3] Cerny, J. (1996) Structural Dependence of CH Bond Absorptivities and Consequences for FTIR Analysis of Coals. Fuel, 75, 1301-1306. http://dx.doi.org/10.1016/0016-2361(96)00103-2

[4] Debashis, B. (2005) Study of Kinetics of Iron Minerals in Coal by Fe-57 Mossbauer and FT-IR Spectroscopy during Natural Burning. Hyperfine Interactions, 163, 167-176.

[5] Manoj, B. (2013) Bio-Demineralization of Indian Bituminous Coal by Aspergillus niger and Characterization of Products. Research Journal of Biotechnology, 8, 49-54.

[6] Manoj, B. and Kunjomana, A.G. (2012) Structural Characterization of Selected Indian Coals by X-Ray Diffraction and Spectroscopic Techniques. Trends in Applied Sciences Research, 7, 434-444.

[7] Manoj, B. and Kunjomana, A.G. (2012) Chemical Leaching of an Indian Bituminous Coal and Characterization of the Products by Vibrational Spectroscopic Techniques. International Journal of Minerals, Metallurgy and Materials, 19, 279-283. http://dx.doi.org/10.1007/s12613-012-0551-0

[8] Manoj, B. and Elcey, C.D. (2010) Demineralization of Coal by Stepwise Leaching: A Study of Sub-Bituminous Indian Coal by FTIR and SEM. Journal of the University Chemical Technology and Metallurgy, 45, 385-390.

[9] Manoj, B. and Kunjomana, A.G. (2010) Chemical Solubilization of Coal Using HF and Characterization of the Products by FTIR, FT Raman, SEM and Elemental Analysis. Journal of Minerals and Materials Characterization and Engineering, 9, 919-928.

[10] Manoj, B. and Kunjomana, A.G. (2010) FT-Raman Spectroscopic Study of Indian Bituminous and Sub-Bituminous Coal. Asian Journal of Material Science, 2, 204-210.

[11] Manoj, B., Kunjomana, A.G. and Chandrasekharan, K.A. (2009) Chemical Leaching of Low Rank Coal and Its Characterization Using SEM/EDAX and FTIR. Journal of Minerals and Materials Characterization and Engineering, 8, 821-832.

[12] Manoj, B. and Elcey, C.D. (2013) Demineralization of Sub-Bituminous Coal by Fungal Leaching-A Structural Characterization by X-Ray and FTIR Analysis. Research Journal of Chemistry and Environment, 17, 11-15.

[13] Narayanan, P. and Manoj, B. (2013) Study of Changes to the Organic Functional Groups of a High Volatile Bituminous Coal during Organic Acid Treatment Process by FTIR Spectroscopy. Journal of Minerals and Materials Characterization and Engineering, 1, 39-43.

[14] Sharma, D.K. and Wadhwa, G. (1997) Demineralization of Coal by Stepwise Bioleaching: A Comparative Study of Three Indian Coals by Fourier Transform Infrared and X-Ray Diffraction Techniques. World Journal of Microbiology and Biotechnology, 13, 29-36. http://dx.doi.org/10.1007/BF02770804

[15] Supaluknari, S., Larkins, F.P., Redlich, P., et al. (1988) An FTIR Study of Australian Coals: Characterization of Oxygen Functional Groups. Fuel Processing Technology, 19, 123-140. http://dx.doi.org/10.1016/0378-3820(88)90061-6 